\title{
Publisher's Note: Focusing Acoustic Beams with a Ball-Shaped Lens beyond the Diffraction Limit [Phys. Rev. Applied 8, 024013 (2017)]
}

\section{J. H. Lopes, M. A. B. Andrade, J. P. Leão-Neto, J. C. Adamowski, I. V. Minin, and G. T. Silva} (Received 5 September 2017; published 19 September 2017)

DOI: 10.1103/PhysRevApplied.8.039901

This paper was published online on 18 August 2017 with an incorrect author affiliation and an omission in the acknowledgments section. I. V. Minin's affiliation should read as "National Research Tomsk Polytechnic University, Tomsk, 30, Lenin Avenue, Russia, 634050." The last sentence of the acknowledgments should read as "I. V. Minin was partially supported by Tomsk Polytechnic University Competitiveness Enhancement Program grant, Project No. TPU CEP_INDT_7612017." The author's affiliation and acknowledgments have been corrected as of 13 September 2017. 